\title{
PENGARUSUTAMAAN GENDER DALAM KEGIATAN BELAJAR DAN PEMBELAJARAN PADA SEKOLAH DASAR DI DKI JAKARTA
}

\author{
Arita Marini \\ e-mail: arita250268@yahoo.co.id \\ PGSD Universitas Negeri Jakarta
}

Jalan Setiabudi 1 No. 1 Jakarta Selatan

\begin{abstract}
Abstrak: Tujuan dari penelitian ini adalah untuk mengetahui implementasi pengarusutamaan gender dalam proses belajar dan pembelajaran di sekolah dasar di Jakarta. Penelitian ini menggunakan metode survei untuk 30 responden yang dilakukan di 30 sekolah dasar di Jakarta. Indikator pengarusutamaan gender dalam proses belajar dan pembelajaran terkait dengan hukuman yang diberikan kepada siswa, peran yang dimainkan oleh siswa, metode pembelajaran bagi siswa, penghargaan diberikan kepada siswa, penghargaan diberikan kepada siswa, evaluasi, dan partisipasi siswa. Hasil penelitian menunjukkan bahwa rata - rata skor pengarusutamaan gender dalam proses belajar dan pembelajaran mencapai 21,17 atau $88,19 \%$ dari nilai maksimum secara teoretis. Artinya, penerapan pengarusutamaan gender dalam proses belajar dan pembelajaran pada $88,19 \%$ dari 30 sekolah dasar sudah berjalan efektif. Pengarusutamaan gender dalam proses belajar dan pembelajaran di 30 sekolah dasar mencapai $43,33 \%$ lebih tinggi daripada rata-rata skor sedangkan 26,66\% lebih rendah dari rata-rata skor. Dapat disimpulkan bahwa penerapan pengarusutamaan gender dalam proses belajar dan pembelajaran di 43,33\% dari 30 sekolah dasar sudah efektif. Dengan kata lain, pengarusutamaan gender dalam proses belajar dan pembelajaran di 13 sekolah dasar sudah efektif. Di sisi lain, implementasi pengarusutamaan gender dalam proses belajar dan pembelajaran belum optimal.
\end{abstract}

Kata kunci: pengarusutamaan gender, proses belajar dan pembelajaran, peran siswa, partisipasi siswa.

\section{GENDER MAINSTREAMING OF INSTRUCTIONAL AND LEARNING PROCESS IN ELEMENTARY SCHOOL AT DKI JAKARTA}

\begin{abstract}
The purpose of this study is to find out the implementation of gender mainstreaming in teaching learning process at elementary schools in Jakarta. This research used survey method for 30 respondents conducted at 30 elementary schools in Jakarta. Indicators of gender mainstreaming in teaching learning process were related to punishment given to the students, roles played by the students, teaching method for the students, opportunities given to the students, rewards given to the students, evaluation, and students' participations. The result of study shows that mean score of gender mainstreaming in teaching learning process reached 21.17 or $88.19 \%$ from theoretically maximum score. It means that implementation of gender mainstreaming in teaching learning process at $88.19 \%$ from 30 elementary school has already been effective. Gender mainstreaming in teaching learning process at 30 elementary schools achieved $43.33 \%$ higher than average score whereas $26.66 \%$ lower than average score. It can be concluded that implementation of gender mainstreaming in teaching learning process at $43.33 \%$ from 30 elementary schools has already been effective. In other words, gender mainstreaming in teaching learning process at 13 elementary schools has already been effective. On the other hand, implementation of gender mainstreaming in teaching learning process has not been optimal.
\end{abstract}

Keywords: gender mainstreaming, teaching learning process, students' roles, students' participations.

\section{PENDAHULUAN}

Hasil survey lembaga-lembaga internasional menunjukkan potret mutu hasil pendidikan yang berkaitan dengan beberapa masalah gender masih belum menggembirakan. Di beberapa sekolah terdapat ketidakseimbangan gender yang jelas karena adanya nilai sosial masyarakat Indonesia.
Bias gender masih terjadi di beberapa sekolah khususnya untuk bahasa dan studi sosial. Selain itu, masih terdapat inefisiensi di dalam proses belajar dan pembelajaran yang disebabkan rendahnya tingkat partisipasi perempuan. Institusionalisasi ketidakseimbangan gender masih banyak terjadi karena jarangnya perempuan yang menempati posisi di dalam pengambilan keputusan. Berbagai analisis 
juga menunjukkan jumlah perempuan yang putus sekolah lebih besar dibandingkan dengan jumlah laki-laki yang putus sekolah. Hasil analisis gender menunjukkan perlu dilakukan reformulasi kebijakan pendidikan yang bersifat responsif terhadap gender. Dengan memperhatikan potret kurang menggembirakan pendidikan di Indonesia, maka perlu dilakukan peningkatan kesetaraan gender di dalam pendidikan secara lebih sistematis. Penelitian ini bertujuan untuk mengetahui implementasi pengarusutamaan gender dalam kegiatan belajar dan pembelajaran di sekolah dasar.

Menurut M.A. Hitt et. al. (2009), manajemen adalah kekuatan utama di dalam setiap organisasi yang mengkoordinasikan aktivitas dari berbagai sistem di dalam mencapai tujuan organisasi tersebut. Manajemen meliputi pengetahuan, seni, dan prinsipprinsip yang berhubungan dengan manajemen organisasi.

Menurut pendapat Robbins \& Coulter (2007) \& Dessler (2001), sebagai sebuah proses, manajemen meliputi hubungan antarmanusia, pengelolaan sumber daya fisik dan finansial, perencanaan, organisasi, pembuatan keputusan, pelaksanaan, pengarahan, dan pengawasan orang-orang di dalam usaha mencapai tujuan yang diinginkan.

Mejia \& Balkin (2002) berpendapat bahwa manajemen dapat didefinisikan sebagai sebuah proses yang terdiri dari perencanaan, pengorganisasian, pengarahan, dan pengawasan di dalam pencapaian tujuan yang telah ditetapkan dengan menggunakan sumber daya manusia dan sumber daya lainnya.

M. Dash \& N. Dash (2008) berpendapat bahwa sekolah dasar merupakan suatu organisasi sosial yang memiliki tujuan tertentu, dimana tujuan utamanya adalah mencapai pendidikan yang berkualitas bagi siswanya. Sekolah dasar memiliki pegawai dan guru sebagai sumber daya manusianya, sumber daya finansial, material, dan fisik.

Panda, U. N. (2008) menyatakan bahwa manajemen sekolah dasar merupakan kegiatan untuk mengelola sekolah dasar. Hal ini berarti manajemen sekolah dasar adalah usaha penggunaan sumber daya manusia dan sumber daya lainnya dalam usaha mencapai tujuan sekolah dasar tersebut secara efektif dan efisien. Di sekolah dasar tersebut, kepala sekolah sebagai manajer perlu menggunakan secara tepat sumber daya manusia, material, dan keuangan dalam usaha mencapai tujuan sekolah dasar tersebut.

K. B. Everard, G. Morris, \& I Wilson (2004) menyatakan bahwa manajemen sekolah dasar merupakan usaha manusia dalam bekerja sama.
Walaupun kepala sekolah berfungsi sebagai manajer sekolah dasar, tetapi kerjasama antara guru, orang tua, siswa, dan anggota masyarakat merupakan hal yang esensial untuk manajemen sekolah dasar secara efektif. Walaupun komputer pada saat ini digunakan secara meningkat di dalam manajemen sekolah dasar, tetapi elemen manusia merupakan kunci tercapainya manajemen sekolah dasar yang efektif.

R. Subrahmanian (2007) berpendapat bahwa pendidikan pada perempuan merupakan kunci utama agar terjadi transfer pengetahuan antar generasi, keseimbangan gender jangka panjang, dan perubahan sosial. Keseimbangan gender di dalam pendidikan pada saat menempati tempat sentral di dalam kebijakan global di dalam hal pembangunan manusia dan sosial. Hasil yang diperoleh dari pendidikan pada perempuan cukup signifikan, tetapi di lain pihak mudah terpengaruh terhadap perubahan yang terjadi di dalam lingkungan ekonomi dan sosial. Perempuan juga masih berjuang untuk menyamakan kedudukannya dengan laki-laki di dalam hal pendaftaran untuk masuk sekolah dan pencapaian prestasi yang diperoleh.

Menurut R. Tiessen (2007), secara umum pengarusutamaan gender berkaitan dengan pembuatan keseimbangan gender yang terpusat pada semua aktivitas. Perubahan nyata dari pengarusutamaan gender meliputi perhatian terhadap distribusi kekuasaan dan lebih sulit untuk dicapai karena membutuhkan komitmen yang lebih dalam untuk mengubah norma dan prosedur suatu organisasi. Pengarusutamaan gender secara luas dipahami sebagai sebuah strategi untuk institusionalisasi dan integrasi perhatian gender ke dalam pengarusutamaan. Pengarusutamaan gender di dalam analisis organisasi secara luas dipahami sebagai proses mentransformasikan institusi dan organisasi untuk mempromosikan keseimbangan gender.

J. R. Frankson (2000) berpendapat bahwa gender merupakan suatu konsep yang menunjuk pada sebuah sistem peran dan hubungan antara laki-laki dan perempuan yang lebih ditentukan oleh konteks politik, ekonomi, sosial dan kebudayaan dibanding konteks biologi. Jenis kelamin biologi seseorang diberikan secara alamiah, di lain pihak gender dikonstruksi secara sosial yaitu suatu proses dimana individu dilahirkan ke dalam kategori biologi laki-laki dan perempuan melalui pemerolehan secara lokal dengan atribut yang disebut maskulin dan feminin. Perilaku yang dipelajari menghasilkan identitas gender dan menentukan peran gender.

Sutherland, E. \& Addy. (2008) menyatakan 
bahwa baik guru dan murid di sekolah sudah memiliki titik pandang tertentu mengenai bagaimana laki-laki dan perempuan berperilaku, dimana organisasi di sekolah juga memperkuat keadaan ini. Pekerjaanpekerjaan seperti mengambil minum, membersihkan ruangan kelas, dan memasak biasanya ditugaskan kepada murid dan guru perempuan.

\section{METODE PENELITIAN}

Penelitian ini menggunakan metode survey pada 30 guru di 30 sekolah dasar di DKI Jakarta. Penelitian ini dilakukan pada bulan Maret sampai dengan November Tahun 2015. Sekolah dasar yang diobservasi di wilayah Jakarta Pusat terdiri dari 4 sekolah dasar yaitu SDI Al-Badar, SDS Trisula Perwari I, SDSN 12 Pagi Bendungan Hilir, dan SDS Muhammadiyah 56. Sekolah dasar yang diobservasi di wilayah Jakarta Timur terdiri dari 12 sekolah dasar yaitu SDN Malaka Sari 04 Pagi, SDI At-Taqwa, SDS Muhammadiyah 24, SDS Angkasa I, SDS Angkasa III, SDS Angkasa IV, SDS Angkasa VII, SDI 19 Al-Azhar Sentra Primer, SDI Islam Al-Azhar 13, SDI DAQTA, SDS Nizamia Andalusia, dan SDI PB. Soedirman. Sekolah dasar yang diobservasi di wilayah Jakarta Barat terdiri dari 4 sekolah dasar, yaitu SDI AlChasanah, SDI Al-Mukhlisin, MI Assa'adatul Abadiyah, dan SDN 04 Kedoya Selatan. Sekolah dasar yang diobservasi di wilayah Jakarta Selatan terdiri dari 8 sekolah dasar, yaitu SDI Al-Syukro Universal, SDS Budi Wanita, SDS Al-Mubasysyirin, SDS Diniah Aisyiyah, SDS Pelita Hati, SDI Islam Mubasysyirin, SDS Ar-Rahman Motik, dan SD laboratorium PGSD FIP UNJ. Sekolah dasar yang diobservasi di wilayah Jakarta Utara terdiri dari 2 sekolah dasar, yaitu SDS Taman Permata Indah dan SDS Hang Tuah VI Pagi.

Pengumpulan data dilakukan dengan penyebaran kuesioner, observasi, dan wawancara. Analisis data menggunakan statistik deskriptif dengan distribusi dan histogram frekuensi. Observasi pengarusutamaan gender di dalam kegiatan belajar mengajar pada 30 sekolah dasar dilakukan di dalam kelas pada saat proses pembelajaran berlangsung.

\section{HASIL DAN PEMBAHASAN}

\section{Hasil}

Indikator-indikator pengarusutamaan gender di dalam kegiatan belajar dan pembelajaran di sekolah dasar pada 30 sekolah dasar adalah pemilihan ketua kelompok di dalam pembelajaran, pemberian kesempatan yang sama untuk menyampaikan pendapat, pendistribusian perhatian yang merata di dalam pembelajaran, pemberian kesempatan yang sama di dalam pengajuan pertanyaan antara murid laki-laki dan perempuan, pemberian layanan remedial dan pengayaan, pemberian perlakuan yang sama di dalam peran yang dilakukan, penggunaan metode pembelajaran, bahasa yang digunakan dalam menyampaikan pesan pembelajaran, pendekatan pembelajaran yang mendorong potensi, penghargaan yang diberikan, jenis kegiatan olahraga, pemberian kesempatan untuk menjadi ketua kelompok diskusi, penilaian hasil belajar, partisipasi di dalam kegiatan pembelajaran, pemberian kesempatan yang sama untuk maju ke depan kelas yang menunjukkan bakat, dan pemberian kesempatan yang sama dalam menjawab pertanyaan.

Pengarusutamaan gender dalam kegiatan belajar dan pembelajaran mencapai maksimum yaitu sebesar $100 \%$ pada aspek pengamatan tentang pemberian peran yang sama antara murid laki-laki dan perempuan di dalam pembelajaran yaitu pemberian kesempatan yang sama untuk menyampaikan pendapat, pemberian kesempatan yang sama di dalam pengajuan pertanyaan antara murid laki-laki dan perempuan, pemberian layanan remedial dan pengayaan yang sama untuk murid laki-laki dan perempuan, pemberian kesempatan yang sama untuk maju ke depan kelas mengerjakan soal bagi murid lakilaki dan perempuan, tidak terdapat perbedaan antara murid laki-laki dan perempuan pada pembagian kelompok dalam proses pembelajaran, pemberian kesempatan yang sama untuk peran laki-laki dan perempuan pada contoh yang diberikan guru dalam pembelajaran, penggunaan metode belajar yang menjamin partisipasi yang seimbang antara murid laki-laki dan peremuan di dalam pembelajaran, pemberian kesempatan yang sama pada murid lakilaki dan perempuan untuk berpartisipasi di dalam kegiatan pembelajaran, pemberian kesempatan yang sama untuk maju ke depan kelas yang menunjukkan bakat bagi murid laki-laki dan perempuan, serta pemberian kesempatan yang sama untuk menjadi ketua kelompok pada setiap kegiatan kelompok kecil di kelas bagi murid laki-laki dan perempuan.

Pengamatan terhadap pengarusutamaan gender dalam kegiatan belajar dan pembelajaran di 30 Sekolah Dasar (SD), menggunakan instrumen observasi yang terdiri dari 24 butir, dengan skala dikotomi, yaitu 0 dan 1 , pemberian skor 0 artinya tidak sesuai, salah, tidak sempurna, tidak memenuhi syarat, 
tidak ada, buruk, tidak setuju, dan lain-lain, sedangkan skor 1 artinya sesuai, benar, sempurna, memenuhi syarat, ada, baik, setuju yang menunjukkan penerapan pengarusutamaan gender dalam kegiatan belajar dan pembelajaran di 30 Sekolah Dasar (SD) sudah baik. Skor teoretik minimum adalah 0 dan maksimum adalah 24. Berdasarkan hasil pengolahan data empirik, hasil pengamatan tentang pengarusutamaan gender di dalam kegiatan pembelajaran disajikan pada Tabel 1.

Tabel 1. Statistik Deskriptif Skor Pengarusutamaan Gender dalam Kegiatan Belajar dan Pembelajaran

\begin{tabular}{ll}
\hline Jenis Statistik Deskriptif & Nilai \\
\hline Mean & 21.17 \\
Standard Error & 0.22 \\
Median & 21 \\
Mode & 22 \\
Standard Deviation & 1.206 \\
Sample Variance & 1.454 \\
Kurtosis & 0.972 \\
Skewness & -0.342 \\
Range & 6 \\
Minimum & 18 \\
Maximum & 24 \\
Sum & 635 \\
\hline Count & 30 \\
\hline
\end{tabular}

Pada Tabel 1 ditunjukkan bahwa rerata skor pengamatan pengarusutamaan gender dalam kegiatan belajar dan pembelajaran adalah 21,17, atau sekitar 88,19\% pencapaian dari skor maksimum teoritik. Pengamatan pengarusutamaan gender dalam kegiatan belajar dan pembelajaran dari 30 sekolah dasar disajikan dalam tabel distribusi frekuensi pada tabel 2, sedangkan histogram frekuensi ditunjukkan pada gambar 1 .

Tabel 2. Distribusi Frekuensi Skor Pengarusutamaan Gender dalam Kegiatan Belajar dan Pembelajaran

\begin{tabular}{ccccc}
\hline No & $\begin{array}{c}\text { Skor } \\
\text { Pengamatan }\end{array}$ & $\begin{array}{c}\text { Frequency } \\
(\mathrm{fi})\end{array}$ & $\begin{array}{c}\text { Relative } \\
\text { frequency } \\
(\%)\end{array}$ & $\begin{array}{c}\text { Cumulative } \\
\text { frequency } \\
(\%)\end{array}$ \\
\hline 1 & 24 & 1 & 3.33 & 3 \\
2 & 23 & 1 & 3.33 & 6.67 \\
3 & 22 & 11 & 36.67 & 43.33 \\
4 & 21 & 9 & 30.00 & 73.33 \\
5 & 20 & 6 & 20.00 & 93.33 \\
6 & 19 & 1 & 3.33 & 96.67 \\
7 & 18 & 1 & 3.33 & 3.33 \\
\hline & Jumlah & 30 & 100 & \\
\hline
\end{tabular}

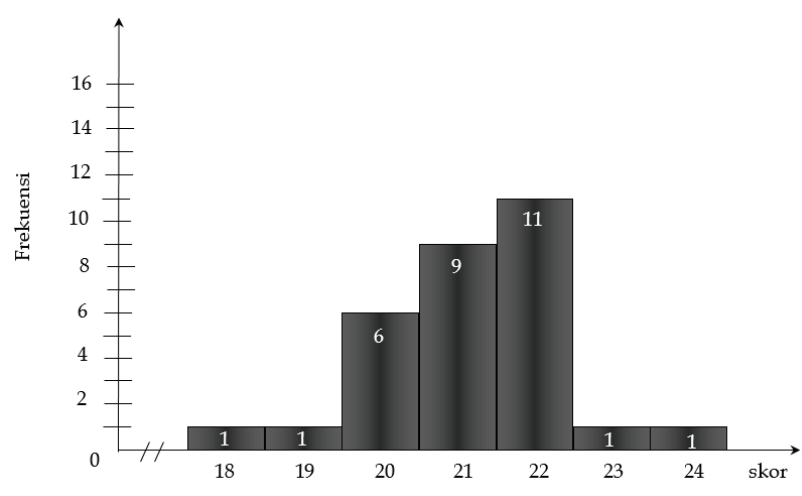

Gambar 1. Histogram frekuensi skor pengarussutamaan gender dalam kegiatan belajar dan pembelajaran

\section{Pembahasan}

Pada 30 sekolah dasar yang diamati ditunjukkan bahwa sudah dilakukan pengarusutamaan gender dalam kegiatan belajar dan pembelajaran secara efektif pada beberapa aspek pengamatan. Pada 30 sekolah dasar yang diamati sudah efektif di dalam memberikan peran yang sama antara murid laki-laki dan perempuan di dalam pembelajaran yaitu pemberian kesempatan yang sama untuk menyampaikan pendapat. Hal ini menunjukkan bahwa pada 30 sekolah dasar sudah efektif dalam memberikan kesempatan yang sama pada murid lakilaki dan perempuan untuk memberikan pendapat di dalam kegiatan belajar dan pembelajaran. Pada 30 sekolah dasar juga sudah efektif dalam memberikan kesempatan yang sama pada murid laki-laki dan perempuan untuk mengajukan pertanyaan di dalam kegiatan belajar dan pembelajaran. Efektivitas pemberian layanan remedial dan pengayaan yang sama untuk murid laki-laki dan perempuan juga sudah dilakukan oleh 30 sekolah dasar yang diamati.

Pada 30 sekolah dasar sudah efektif dalam memberikan kesempatan yang sama untuk maju ke depan kelas dalam mengerjakan soal bagi murid laki-laki dan perempuan. Hasil pengamatan juga menunjukkan bahwa pada 30 sekolah dasar tidak terdapat perbedaan antara murid laki-laki dan perempuan pada pembagian kelompok dalam proses pembelajaran. Pemberian kesempatan yang sama untuk peran laki-laki dan perempuan pada contoh yang diberikan guru dalam pembelajaran juga sudah efektif pada 30 sekolah dasar yang diamati. Selain itu, pada 30 sekolah dasar yang diamati sudah efektif di dalam menggunakan metode belajar yang menjamin partisipasi yang seimbang antara murid laki-laki dan peremuan di dalam pembelajaran.

Pada 30 sekolah dasar yang diamati juga sudah 
efektif di dalam memberikan kesempatan yang sama pada murid laki-laki dan perempuan untuk berpartisipasi di dalam kegiatan pembelajaran. Pada 30 sekolah dasar yang diamati sudah efektif di dalam memberikan kesempatan yang sama untuk maju ke depan kelas yang menunjukkan bakat bagi murid laki-laki dan perempuan. Pemberian kesempatan yang sama untuk menjadi ketua kelompok pada setiap kegiatan kelompok kecil di kelas bagi murid laki-laki dan perempuan juga sudah efektif dilakukan oleh 30 sekolah dasar yang diamati.

Rerata skor pengamatan pengarusutamaan gender dalam kegiatan belajar dan pembelajaran yang ditunjukkan pada Tabel 1 adalah 21,17, atau sekitar $88,19 \%$ pencapaian dari skor maksimum teoritik. Hal ini berarti penerapan pengarusutamaan gender dalam kegiatan belajar dan pembelajaran sudah mencapai 88,19 \% dari 30 sekolah dasar. Dapat disimpulkan bahwa pada 30 sekolah dasar yang diamati, 26 sekolah sudah efektif di dalam melaksanakan pengarusutamaan gender pada kegiatan belajar dan pembelajaran ditinjau dari aspek pengamatan pemilihan ketua kelompok di dalam pembelajaran, pemberian kesempatan yang sama untuk menyampaikan pendapat, pendistribusian perhatian yang merata di dalam pembelajaran, pemberian kesempatan yang sama di dalam pengajuan pertanyaan antara murid laki-laki dan perempuan, pemberian layanan remedial dan pengayaan, pemberian perlakuan yang sama di dalam peran yang dilakukan, penggunaan metode pembelajaran, bahasa yang digunakan dalam menyampaikan pesan pembelajaran, pendekatan pembelajaran yang mendorong potensi, penghargaan yang diberikan, jenis kegiatan olahraga, pemberian kesempatan untuk menjadi ketua kelompok diskusi, penilaian hasil belajar, partisipasi di dalam kegiatan pembelajaran, pemberian kesempatan yang sama untuk maju ke depan kelas yang menunjukkan bakat, dan pemberian kesempatan yang sama dalam menjawab pertanyaan.

Berdasarkan sebaran data yang ditunjukkan pada tabel 2, pengarusutamaan gender dalam kegiatan belajar dan pembelajaran di 30 sekolah dasar yang memiliki skor di atas rata-rata sebanyak 43,33\%. Hal ini berarti 13 sekolah dasar dari 30 sekolah dasar yang diamati sudah memiliki efektivitas yang baik atau di atas rata-rata di dalam melakukan pengarusutamaan gender pada kegiatan belajar dan pembelajaran ditinjau dari aspek pengamatan pemilihan ketua kelompok di dalam pembelajaran, pemberian kesempatan yang sama untuk menyampaikan pendapat, pendistribusian perhatian yang merata di dalam pembelajaran, pemberian kesempatan yang sama di dalam pengajuan pertanyaan antara murid laki-laki dan perempuan, pemberian layanan remedial dan pengayaan, pemberian perlakuan yang sama di dalam peran yang dilakukan, penggunaan metode pembelajaran, bahasa yang digunakan dalam menyampaikan pesan pembelajaran, pendekatan pembelajaran yang mendorong potensi, penghargaan yang diberikan, jenis kegiatan olahraga, pemberian kesempatan untuk menjadi ketua kelompok diskusi, penilaian hasil belajar, partisipasi di dalam kegiatan pembelajaran, pemberian kesempatan yang sama untuk maju ke depan kelas yang menunjukkan bakat, dan pemberian kesempatan yang sama dalam menjawab pertanyaan.

Berdasarkan sebaran data yang ditunjukkan pada Tabel 2, pengarusutamaan gender dalam kegiatan belajar dan pembelajaran di 30 sekolah dasar yang memiliki skor di bawah rata-rata sebanyak $26,66 \%$. Hal ini berarti 8 sekolah dasar dari 30 sekolah dasar yang diamati memiliki efektivitas yang belum baik atau di bawah rata-rata di dalam melakukan pengarusutamaan gender pada kegiatan belajar dan pembelajaran ditinjau dari aspek pengamatan pemilihan ketua kelompok di dalam pembelajaran, pemberian kesempatan yang sama untuk menyampaikan pendapat, pendistribusian perhatian yang merata di dalam pembelajaran, pemberian kesempatan yang sama di dalam pengajuan pertanyaan antara murid laki-laki dan perempuan, pemberian layanan remedial dan pengayaan, pemberian perlakuan yang sama di dalam peran yang dilakukan, penggunaan metode pembelajaran, bahasa yang digunakan dalam menyampaikan pesan pembelajaran, pendekatan pembelajaran yang mendorong potensi, penghargaan yang diberikan, jenis kegiatan olahraga, pemberian kesempatan untuk menjadi ketua kelompok diskusi, penilaian hasil belajar, partisipasi di dalam kegiatan pembelajaran, pemberian kesempatan yang sama untuk maju ke depan kelas yang menunjukkan bakat, dan pemberian kesempatan yang sama dalam menjawab pertanyaan.

Penerapan pengarusutamaan gender dalam kegiatan belajar dan pembelajaran yang ditunjukkan pada gambar 1 dilihat dari sebaran data skor pengamatan/observasi lapangan di 30 Sekolah Dasar (SD) di DKI Jakarta. Delapan sekolah dasar menunjukkan penerapan pengarusutamaan gender dalam kegiatan belajar dan pembelajaran belum efektif, sedangkan pada tiga belas sekolah dasar menunjukkan penerapan pengarusutamaan gender dalam kegiatan belajar dan pembelajaran sudah efektif. 


\section{PENUTUP}

\section{Kesimpulan}

Rerata skor pengamatan pengarusutamaan gender dalam kegiatan belajar dan pembelajaran adalah 21,17 , atau sekitar $88,19 \%$ pencapaian dari skor maksimum teoretik yang berarti penerapan pengarusutamaan gender dalam kegiatan belajar dan pembelajaran di 88,19\% dari 30 sekolah dasar sudah efektif. Pengarusutamaan gender dalam kegiatan belajar dan pembelajaran di 30 sekolah dasar yang memiliki skor di atas rata-rata sebanyak $43,33 \%$ dan sekitar 26,66\% dengan skor pengamatan di bawah rata-rata. Hal ini berarti penerapan pengarusutamaan gender dalam kegiatan belajar dan pembelajaran pada $43.33 \%$ dari 30 sekolah dasar yang diamati dapat dikatakan sudah cukup baik/positif.

\section{Saran}

Agar sekolah dasar di DKI Jakarta dapat menerapkan pengarusutamaan gender dalam kegiatan belajar dan pembelajaran tercapai keseimbangan gender. Pengarusutamaan gender dalam kegiatan belajar dan pembelajran dapat dilakukan melalui pemberian peran yang sama di dalam pembelajaran dan pemberian kesempatan yang sama untuk berpartisipasi dalam pembelajaran bagi murid lakilaki dan perempuan.

\section{DAFTAR PUSTAKA}

Dash, M., \& Dash, N. (2008). School management. New Delhi: Atlantic Publishers and Distributors (P) Ltd.

Everard, K. B., Morris, G, \& Wilson, I. (2004). Effective school management. California: Sage Publication Inc.

Frankson, J. R. (2000). A quick guide to: Gender mainstreaming in information and communications. UK: Commonwealth Secretariat.

Gomez-Mejia, L.R. \& Balkin, D.B. (2002). Management. New York: McGraw-Hill.

Hitt, M.A. et.al. (2009). Management. Second Edition. New Jersey: Prentice Hall.

Panda, U. N. (2008). School management. New Delhi: APH Publishing Corporation.

Peraturan Menteri Pendidikan Nasional No. 84 Tahun 2008 tentang Pedoman Pelaksanaan Pengarusutamaan Gender Bidang Pendidikan. Robbins, S.P. \& Coulter, M. (2007). Management. Ninth Edition. New Jersey: Prentice Hall.

Subrahmanian, R. (2007). Gender in primary and secondary education. UK: Commonwealth Secretariat.

Sutherland, E. \& Addy. (2008). Gender equity in junior and senior secondary education in sub-saharan Africa. USA: The World Bank.

Tiessen, R. (2007). Everywhere/nowhere: Gender mainstreaming in development agencies. USA: Kumarian Press, Inc. 